\title{
Interleukin 6 strongly correlates with malnutrition inflammation score and it is strong predictor for mortality in hemodialysis patients
}

\begin{abstract}
Background: Among chronic kidney dialysis patients the morbidity and mortality rate is high, with recent evidence suggested that this may be linked to inflammation. The activity of IL-6 plays a pivotal role in inflammation, being the most powerful inducer of the acute-phase response, and markedly up-regulated in end stage renal diseases (ESRD) patients and serum IL-6 levels predict outcome of hemodialysis (HD) patients. Studies are performed to investigate the relationship between serum IL-6 and the nutritional status among chronic hemodialysis patients.
\end{abstract}

Methodology: The study was conducted at Sri Ramachandra University Hospital, descriptive cross-sectional design with fifty three patients were recruited using convenient sampling technique which is of non-probability type and Pre dialysis blood samples were taken for IL 6. The Malnutrition Inflammation Score (MIS) has 10 components, which is a likert scale ranging from normal to severe. Statistical Analysis was done using SPSS 16.0.

Results: The IL-6 mean score was 16.2 with the SD of 3.4, where as for MIS the mean was 19.77 with SD of 4.49. The Pearson's correlation coefficient values r' $=0.305$ which is statically significant at $p<0.05$ Level. Patients with high score of MIS demonstrated severe degree of malnutrition and inflammation. This reveals that increase in MIS leads to elevation of IL -6 , which indicates that the patients are gradually developing inflammation when unidentified can even cause mortality.

Conclusion: Study finding suggests that patients must be monitored for MIS score periodically rather than testing IL-6 levels, which can be and a cost effective methods for the patients.

Keywords: inflammation, malnutrition, hemodialysis, interleukin 6
Volume 2 Issue 2 - 2015

Thiagarajan Thandavan,' Georgi Abraham, ${ }^{2}$ Soundararajan $\mathrm{P}^{3}$ Chandrasekaran $\mathrm{V}^{4}$

'SRM Medical College Hospital \& Research Centre, India 2Medicine and Nephrology, Pondicherry Institute of Medical Science, India

${ }^{3}$ Department of Nephrology and Renal Transplantation, Sri Ramachandra Medical College and Research Institute, India ${ }^{4}$ Nephrology and Renal Transplant Physician Kidney Institute, Global Hospitals \& Health City, India

Correspondence: Thiagarajan Thandavan, Renal Science and Dialysis Technology, Department of Nephrology, and Renal Transplantation, SRM Medical College Hospital and Research Centre, Kattankulathur, Potheri, India, Tel 9380873891, Email tdrthiaga@gmail.com

Received: December 23, 2014 | Published: March 19, 2015
Abbreviations: ESRD, end stage renal diseases; HD, hemo dialysis; MIS, malnutrition inflammation score

\section{Introduction}

The annual morbidity and mortality rate in dialysis patients remains high despite the marked improvement in dialysis technology and patient care. Many hemodialysis (HD) patients ${ }^{1-4}$ show increase in IL 6 , which is indicated by increased circulating levels of nonspecific markers of inflammation. IL-6 plays an important role in inflammation, being the most potent inducer of the acute-phase response. ${ }^{5}$ Nutritional status is important to analysis the CKD patients for morbidity and mortality ${ }^{6,7}$ as well as in their quality of life and ultimate rehabilitative potential.

\section{Aim of the study}

To analysis the relationship between interleukin 6 and malnutrition inflammation score among hemodialysis patients.

\section{Methodology}

\section{Research design}

The research design chosen for this study was descriptive crosssectional design. The researcher collected and documented the data to understand the demographic and biochemical variables of patient undergoing hemodialysis. The investigator also gathered the data to identify the malnutrition by using malnutrition questionnaire.

\section{Sample}

Patients who fulfilled the inclusion criteria.

\section{Sample size}

A total of fifty three (53) patients who underwent hemodialysis.

\section{Data collection}

Data were collected by structured questionnaire. The questionnaire included information on sociodemographic factors, and malnutrition inflammation score (MIS).

\section{Laboratory evaluation}

Serum albumin and IL 6 venous blood was collected before dialysis.

\section{Statistical analysis}

Statistical Analysis Data were analyzed with descriptive and inferential statistics using SPSS 16.0 statistical package. 


\section{Result}

The IL 6 mean score 16.12 with the SD of 34.10 , whereas for serum albumin, the mean was 3.41 with SD of 0.44 . The Pearson's correlation co-efficient value $r=-0.429$, which statistically evidenced highly negative correlation at $\mathrm{p}<0.01$ level. This shows that if IL 6 increases, then the serum albumin decreases (Table 1) (Table 2). The IL 6 mean score 16.12 with the SD of 34.10, whereas for MIS, the mean was 19.77 with SD of 4.49. The Pearson's correlation co-efficient value $\mathrm{r}=0.304$, which statistically evidenced positive correlation at $\mathrm{p}<0.05$ level. This shows that if IL 6 increases, then the MIS increases (Table 3).

Table I Mean and Standard Deviation of Study Variables among Hemodialysis Patients

\begin{tabular}{lll}
\hline SI. No. & Variables & Mean \pm SD \\
\hline I & Age (in years) & $50.04 \pm 15.26$ \\
2 & Duration of illness (months) & $52.58 \pm 66.28$ \\
3 & Duration of diabetes(months) & $36 \pm 84$ \\
4 & Duration of hypertension(months) & $86.28 \pm 85.921$ \\
5 & Interleukin 6 (pg/ml) & $16 \pm 34$ \\
6 & Serum Albumin $(\mathrm{gm} / \mathrm{dL})$ & $3.4 \pm 0.4$ \\
\hline
\end{tabular}

Table 2 Relationship between Interleukin 6 and Albumin among hemodialysis patients (Correlation co-efficient value)

\begin{tabular}{llll}
\hline \multirow{2}{*}{ Scales } & \multicolumn{3}{l}{ Statistical values } \\
\cline { 2 - 4 } & Mean & SD & r-value \\
\hline Interleukin 6 & 16.12 & 34.1 & $\begin{array}{l}\mathrm{r}=0.429 \\
\mathrm{p}<0.01 \\
\text { (Highly Significant) }\end{array}$ \\
\hline
\end{tabular}

Table 3 Relationship between IL 6 and Malnutrition Inflammation Score (MIS) among hemodialysis patients. (Correlation co-efficient value)

\begin{tabular}{llll}
\hline \multirow{2}{*}{ Scales } & \multicolumn{3}{l}{ Statistical values } \\
\cline { 2 - 4 } & Mean & SD & r-value \\
\hline Interleukin 6 & 16.12 & 34.1 & $\begin{array}{l}\mathrm{r}=0.429 \\
\mathrm{p}<0.0 \mathrm{I} \\
\text { (Highly Significant) }\end{array}$ \\
Serum Albumin & $3.4 \mathrm{I}$ & 0.44 & \\
\hline
\end{tabular}

\section{Discussion}

In this study, that the response of the fifty three maintenance hemodialysis patients to a simple question about malnutrition inflammation score (MIS) of the hemodialysis patients was significantly associated with several measures of inflammatory and nutritional status. During the Study the objective data of IL 6 was measured pre dialysis. In our study, IL 6 was well correlated with biochemical variables and MIS. In our study serum albumin has been shown to be a strong predictor of morbidity and mortality, and other numerous studies have focused on the determinants of level of serum albumin in patients treated with HD. In our study malnutrition and increased inflammation have been the most important factors associated with this biochemical markers. ${ }^{5,8-11}$

In the present study also able to show a relationship of negative correlation between lower serum albumin and the pro-inflammatory cytokines of IL $6 .^{5,12,13}$ In the present study reveals that IL-6 levels independently predict survival for the elevated levels of circulating pro-inflammatory cytokines. The MIS correlating significantly with prospective hospitalizations of MHD patients and was found to be a predictor of mortality in MHD patients. Absolutely, improved correlations between the MIS and morbidity, MIS and mortality occur at least partly because of inclusion criteria of such known markers of outcome as serum albumin level and BMI, which is the reason included in the MIS. This study demonstrate that correlation between the MIS and serum IL 6 level was comparatively positive relationship, perhaps because of serum albumin level, a component of the MIS, is known to negatively correlating with serum IL 6 level.

\section{Conclusion}

The MIS performs to be a convenient, short-term tool to riskstratify MHD patients, which may circumvent the need for measuring inflammatory markers like IL-6. Study finding suggests that patients must be monitored for MIS score periodically rather than testing IL-6 levels, which can be a cost effective methods for the patients.

\section{Acknowledgements}

I would like to thank, Dr. Georgi for his immense support and guidance and also I would like to thank Dr. P. Soundararajan for his support.

\section{Conflict of interest}

The author declares no conflict of interest.

\section{References}

1. Noh H, Lee SW, Kang SW, et al. Serum C-reactive protein: a predictor of mortality in continuous ambulatory peritoneal dialysis patients. Perit Dial Int. 1998;18(4):387-394.

2. Haubitz M, Brunkhorst R, Wrenger E, et al. Chronic induction of Creactive protein by hemodialysis, but not by peritoneal dialysis therapy. Perit Dial Int. 1996;16(2):158-162.

3. Yeun JY, Kaysen GA. Acute phase proteins and peritoneal dialysate albumin loss are the main determinants of serum albumin and peritoneal dialysis patients. Am J Kidney Dis. 1997;30(6):923-927.

4. Zimmermann J, Herrlinger S, Pruy A, et al. Inflammation enhances cardiovascular risk and mortality in hemodialysis patients. Kidney Int. 1999;55(2):648-658.

5. Bologa RM, Levine DM, Parker TS, et al. Interleukin-6 predicts hypoalbuminemia, hypocholesterolemia, and mortality in hemodialysis patients. Am J Kidney Dis. 1998;32(1):107-114.

6. Pecoits-Filho R, Barany P, Lindholm B, et al. Interleukin-6 is an independent predictor of mortality in patients starting dialysis treatment. Nephrol Dial Transplant. 2002;17(9):1684-1688.

7. Stenvinkel P, Barany P, Heimburger O, et al. Mortality, malnutrition, and atherosclerosis in ESRD: What is the role of interleukin-6? Kidney Int Suppl. 2002;61(80):103-108.

8. Ikizler TA, Wingard RL, Harvell J, et al. Association of morbidity with markers of nutrition and inflammation in chronic hemodialysis patients: A prospective study. Kidney Int. 1999;55(5):1945-1951.

9. Kimmel PL, Phillips TM, Simmens SJ, et al. Immunologic function and survival in hemodialysis patients. Kidney Int. 1998;54(1):236-244.

10. Bergstrom J. Nutrition and mortality in hemodialysis. J Am Soc Nephrol. 1995;6(5):1329-1341. 
11. Kaysen GA. Biologic basis of hypoalbuminemia in ESRD. $J$ Am Soc Nephrol. 1998;9(12):2368-2376.

12. Yeun JY, Levine RA, Mantadilok V, et al. C-Reactive protein predicts all-cause and cardiovascular mortality in hemodialysis patients. Am J Kidney Dis. 2000;35(3):469-476.
13. Kaizu Y, Kimura M, Yoneyama T, et al. Interleukin-6 may mediate malnutrition in chronic hemodialysis patients. Am J Kidney Dis. 1998;31(1):93-100 